\title{
ANTICORPOS CONTRA ToXoplasma gondii EM GATOS APREENDIDOS PELO CENTRO DE CONTROLE DE ZOONOSES DE LAGES, SC.
}

\author{
Anderson Barbosa de Moura¹, Natascha Trevisani, Rosiléia Marinho de Quadros, \\ Geanice Ledo, Antonio Pereira de Souza, Amélia Aparecida Sartor \\ 1 Correspondência: anderson.moura@udesc.br:
}

RESUMO: A toxoplasmose é uma zoonose de distribuição mundial. O gato doméstico tem papel importante na epidemiologia da doença por atuar como hospedeiro definitivo, eliminando oocistos que contaminam o ambiente. A sorologia em gatos pode ser considerada um reflexo da contaminação ambiental. Com os objetivos de determinar a ocorrência de anticorpos contra Toxoplasma gondii e identificar possíveis fatores de risco para a infecção em gatos apreendidos pelo Centro de Controle de Zoonoses de Lages, SC, 107 amostras de sangue foram colhidas e remetidas ao Laboratório de Parasitologia e Doenças Parasitárias do CAV/UDESC. A pesquisa de anticorpos foi realizada por meio da Reação de Imunofluorescência Indireta (RIFI) utilizando como antígeno taquizoítos da cepa $\mathrm{RH}$ do protozoário. Foram consideradas positivas amostras reagentes na diluição $\geq 1: 64$. Os dados foram analisados pelos testes exato de Fisher e $x 2(P<0,05)$ para verificar correlação entre soropositividade e o sexo e a idade dos animais. Do total de amostras, $38(35,5 \%)$ foram positivos para $T$. gondii. Houve correlação estatística significativa $(P<0,05)$ entre idade e soropositividade com $79 \%$ (30/38) dos positivos apresentando idade $\geq 13$ meses.

Palavras-chave: epidemiologia, felinos; RIFI; toxoplasmose

\section{(Toxoplasma gondii antibodies in cats captured by the Center for Zoonosis Control of Lages, SC.)}

\begin{abstract}
Toxoplasmosis is a zoonosis of worldwide distribution. The domestic cat has an important role in epidemiology the disease to act as definitive host, eliminating oocysts that contaminate the environment. Serology in cats can be considered a reflection of environmental contamination. Aiming to determine the presence of antibodies against Toxoplasma gondii and identify possible risk factors for infection in cats seized by the Center for Zoonosis Control of Lages, SC, 107 blood samples were collected and sent to the Laboratory of Parasitology and Parasitic Diseases CAV/UDESC. The presence of antibodies was performed by Immunofluorescence Assay Test (IFAT) using as antigen tachyzoites of the $\mathrm{RH}$ strain of the parasite. Reactive samples were considered positive at a dilution $\geq 1: 64$. Data were analyzed by Fisher's exact test and $x 2(P<0.05)$ to verify correlation between seropositivity and sex and age of animals . Of the total sample, $38(35.5 \%)$ were positive for $T$. gondii. There was a statistically significant correlation $(P<0.05)$ between age and seropositivity, with $79 \%(30 / 38)$ of positive presenting aged $\geq 13$ months
\end{abstract}

Key Words: epidemiology, feline; IFAT; toxoplasmosis 


\section{INTRODUÇÃO}

A toxoplasmose é uma doença de caráter zoonótico de distribuição mundial, causada pelo Toxoplasma gondii, protozoário capaz de parasitar animais homeotérmicos. Os membros da Família Felidae (domésticos e selvagens) são hospedeiros definitivos, mas também atuam como hospedeiros intermediários, o que torna o gato fundamental na epidemiologia desta enfermidade (MARTINS e VIANA, 1998).

Ocorre em animais de produção, incluindo ovinos, caprinos, suínos, bovinos, aves, além de animais silvestres e de companhia, como cães e gatos. $\mathrm{Na}$ maioria dos casos, os indivíduos infectados são assintomáticos (DUBEY, 1993), porém na produção animal a infecção pode causar prejuízos. Meerburg et al. (2006) e Ortega-Pacheco et al. (2011) identificaram a importância do gato na epidemiologia da toxoplasmose suína e preconizam a limitação do número e do acesso de gatos às granjas.

Garcia et al. (1999), no Paraná, correlacionaram a soroprevalência para T. gondii em algumas espécies animais e observaram correlação entre os títulos de anticorpos interespécies, positivas e significativas, demonstrando que onívoros, carnívoros e herbívoros estão expostos a vias de transmissão comuns. Os resultados demonstraram a elevada prevalência da toxoplasmose na população estudada e a importância do gato na epidemiologia da toxoplasmose animal e humana.

Nos humanos pode causar aborto, morte fetal, distúrbios neurológicos, etc., entretanto $80 \%$ das infecções primárias por $T$. gondii no homem permanecem assintomáticas, devido à efetividade do sistema imune (Cantos et al., 2000).

Embora uma baixa prevalência da infecção em seres humanos indique menor contato com as fontes de infecção, também significa um maior risco potencial de mulheres adquirirem a primo-infecção durante a gestação com consequente transmissão congênita.

Os gatos são contaminados principalmente pela ingestão de cistos contendo os bradizoítos, localizados nos tecidos dos hospedeiros intermediários, como roedores. O fornecimento de carne crua, principalmente de pequenos ruminantes e suínos, também constitui importante meio de contaminação. Galvan-Ramirez et al. (1999), em Guadalajara, no México, observaram que gatos alimentados com carne crua e que não tinham adequado destino de suas fezes representavam fatores de risco para a toxoplasmose humana. A ingestão de oocistos esporulados também constitui fonte de infecção para os felinos.

São liberados aproximadamente $100.000 / g$ de fezes, excretados durante uma ou duas semanas, e que podem permanecer viáveis por até dois anos (NAVARRO, 2001). Embora a excreção de oocistos pelos gatos seja de curta duração, durante a fase inicial da infecção, eles podem eliminar entre $94 \mathrm{e}$ 4671 oocistos/ m2 levando a uma contaminação substancial do meio (DABRITZ et al., 2007a). O índice de infecção em gatos, especialmente de vida livre, pode ser considerado um indicador do nível de infecção do ambiente por T. gondii (WANG et al., 2012).

Pneumonia é a alteração mais importante no caso da toxoplasmose em gatos, que podem ainda apresentar hepatite, necrose pancreática, miosite e miocardite (DUBEY, 1993). Segundo Svobodová et al. (1998), 90\% dos gatos não manifestam a doença, mesmo com altos títulos na sorologia. Os sinais mais comuns da toxoplasmose em gatos são anorexia, febre, letargia, vômito, perda de peso, aborto, alterações nervosas, 
disfunções oculares, sintomas cardíacos e, eventualmente, morte súbita. Uveíte, catarata e descolamento de retina podem acometer felinos com toxoplasmose (PEARCE et al., 2007). Granuloma toxoplásmico no cérebro foi observado em um gato com crises convulsivas e que apresentava evidência sorológica de infecção ativa por T. gondii (PFOHL e DEWEY, 2005). Os gatinhos infectados ainda no útero materno podem ser abortados ou morrerem logo após o nascimento. Svobodová et al. (1998) consideram a infecção felina por $T$. gondii uma enfermidade oportunista, principalmente em animais infectados com os vírus da imunodeficiência felina (FIV) e da leucemia felina (FeLV), embora DABRITZ et al. (2007b) não tenham observado o mesmo em gatos infectados experimentalmente com FIV. Dorny et al. (2002) observaram correlação entre soroprevalência para $T$. gondii em gatos com FIV, mas não com FeLV.

No Estado de Santa Catarina, Rosa et al. (2010), na cidade de Lages, observaram uma prevalência de 14,33\% (RIFI, 21:64) em gatos domiciliados e verificaram correlação positiva entre a soropositividade e a idade e o acesso à rua e/ou a zona rural. Entretanto em gatos errantes não há dados referentes à região de Lages, SC.

\section{MATERIAL E MÉTODOS}

No período de Janeiro de 2012 a julho de 2013, foram colhidas amostras de sangue de 107 gatos apreendidos pelo Centro de Controle de Zoonoses (CCZ) do município de Lages, no estado de Santa Catarina. $O$ sangue foi encaminhado, acondicionado e identificado, para o Laboratório de Parasitologia e Doenças Parasitárias do Centro de Ciências Agroveterinárias (CAV) da Universidade do Estado de Santa Catarina (UDESC), onde foi obtido o soro que foi armazenado $(-200 C)$ até a realização dos testes.

Para a realização da Reação de Imunofluorescência Indireta (RIFI) para toxoplasmose, foi utilizado como antígeno taquizoítos da cepa $\mathrm{RH}$ de $T$. gondii. Os exames (RIFI) foram realizados de acordo com CAMARGO (1964). Os soros dos gatos foram diluídos em PBS. As amostras que apresentaram reação na diluição 1:64 foram consideradas positivas (COELHO et al., 2011) e estas foram diluídas sequencialmente, em múltiplos de quatro, até diluição máxima reativa para a titulação. Soros controle (positivo e negativo) foram utilizados para comparação.

Informações referentes ao sexo e idade dos animais, assim como os resultados da sorologia, foram tabulados e analisados estatisticamente por meio dos testes exato de Fischer e do quiquadrado para verificar a correlação da ocorrência de anticorpos contra $T$. gondii e as variáveis analisadas.

\section{RESULTADOS E DISCUSSÃO}

Das amostras avaliadas, 38 (35,5\%) foram positivas para T. gondii. A recíproca dos títulos de anticorpos observada foi assim distribuída: 1:64 (12), 1:256 (18) e 1:1024 (oito). Os resultados, detalhados na Tabela 1 , mostram que o protozoário está amplamente distribuído entre os gatos errantes do município de Lages, SC. 


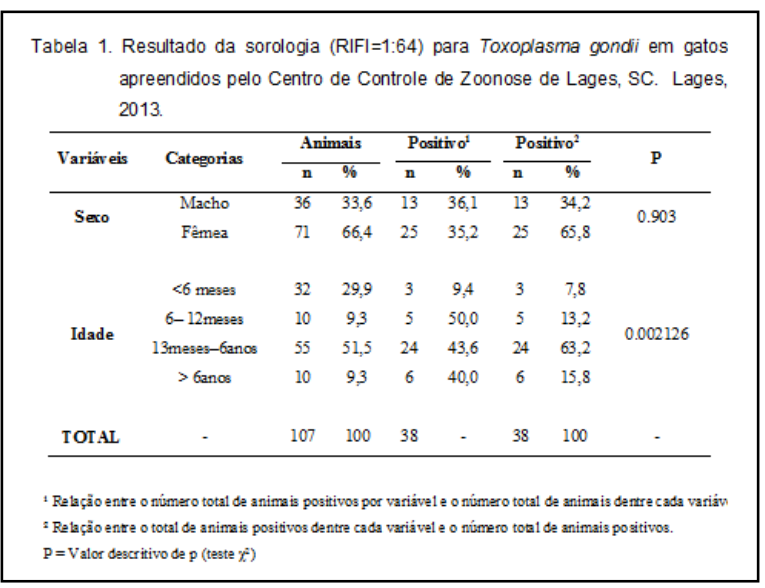

Estudos em diferentes partes do mundo demonstrando a soroprevalência da toxoplasmose felina indicam valores variáveis.

Dubey et al. (2006), na Colômbia, observaram soroprevalência de 45,2\% dos gatos de rua avaliados (MAT, $\geq 1: 10$ ). Oocistos não foram detectados nas fezes de nenhum deles e o isolamento (a partir dos seus tecidos) foi obtido com sucesso dos animais com títulos de anticorpos na diluição $\geq 1: 40$. $\mathrm{Na}$ região do Veneto, Itália, alta prevalência foi observada em gatos de rua, com $69,3 \%$ dos animais apresentando anticorpos contra $T$. gondii (NATALE et al., 2007). Waap et al. (2012), em Portugal, registraram soroprevalência (Aglutinação direta, $1: 20)$ de $44,2 \%$ entre gatos errantes. No Iraque Switzer et al. (2013) verificaram soroprevalência de 30,4\%. Wang et al. (2012) em Xangai, China, observaram $11,7 \%$ de positivos (ELISA, 1:100). Também na China, em Pequim, Weifen et al. (2012), por meio do MAT (1:20), identificaram $57,8 \%$ de positivos.

No Brasil, Meireles et al. (2004), em gatos de rua, relataram $40 \%$ dos animais sororreagentes para $T$. gondii. No Estado de São Paulo, soro de 237 gatos errantes de 15 municípios foram analisados por meio do Teste Modificado de Aglutinação (MAT, $\geq 1: 25$ ) e 84 deles $(35,4 \%)$ foram positivos embora somente três $(1,3 \%)$ apresentaram oocistos de $T$. gondii nas fezes (PENA et al., 2006). Diversos tecidos (língua, musculaturas cardíaca e esquelética e cérebro) foram submetidos ao bioensaio em camundongos e isolou-se $T$. gondii de 47 gatos.

Langoni et al. (2001), em estudo realizado com gatos domiciliados, provenientes de três cidades do Estado de São Paulo e de uma cidade do Paraná, identificaram 19,4\% (37/191) dos animais sororreagentes (RIFI, $\geq 1: 16$ ). Silva et al. (2002), nas cidades de Guarulhos e de São Paulo, analisando amostras de soro de 502 gatos domésticos por meio do MAT $(\geq 1: 20)$, encontraram $26,3 \%$ (132) dos animais positivos para toxoplasmose. Neto et al. (2003), na cidade de Niterói, relatam $24,39 \%$ dos gatos errantes analisados soropositivos (ELLISA e HI) para toxoplasmose. Em Rondônia, Cavalcante et al. (2006), analisando soros de gatos de fazendas com criação de suínos, identificaram alta incidência de soropositivos (87,3\%). Em Santa Isabel do Ivaí, PR, onde grave surto de toxoplasmose humana ocorreu pela ingestão de água contaminada com oocistos de T. gondii, 84,4\% (49/58) dos gatos domiciliados soroconverteram ( $\geq 1: 20$ ) no MAT (DUBEY et al., 2004).

A ocorrência da infecção toxoplásmica observada nos gatos errantes $(35,5 \%)$, no presente estudo, foi maior que em animais domiciliados da mesma região. Rosa et al. (2010) realizaram a colheita de sangue de 300 gatos domiciliados na cidade de Lages e observaram uma prevalência de 14,33\% (RIFI, 21:64). O mesmo foi observado na Espanha, por Miro et al. (2004), que registraram que gatos de rua $(36,9 \%)$ e de áreas rurais $(33,3 \%)$ apresentam soroprevalência maior que gatos domésticos (25,5\%). Entretanto, Dabritz 
et al. (2007b), na Califórnia (EUA), relataram prevalência de $29,6 \%$ e não encontraram diferenças entre gatos domiciliados e errantes.

Gatos errantes são mais susceptíveis a variadas fontes de infecção toxoplásmica, provavelmente pela prática do carnivorismo e, desta forma, adquirem a infecção via ingestão de cistos encontrados nos tecidos de suas presas. Mesmo em animais domiciliados, Rosa et al. (2010), observaram correlação entre sorologia positiva para $T$. gondii e o acesso à rua e/ou a zona rural. Coelho et al. (2011), em Araçatuba, SP, verificaram soropositividade (RIFI, $\geq 1: 64$ ) em 15,7\% dos animais avaliados e somente aqueles com acesso a rua foram positivos. Braga et al. (2012), em São Luís, MA, verificaram, por meio da RIFI $(\geq 1: 40)$, que gatos semi-domiciliados apresentam elevada sorologia positiva (50,5\%) para T. gondii.

Os resultados do presente estudo indicam correlação entre sorologia positiva e idade $(p<0,05)$, com $79 \%$ dos positivos apresentando idade $\geq 13$ meses (Tabela 1), o que sugere a ocorrência da transmissão horizontal e corrobora a hipótese do carnivorismo como principal forma de infecção destes animais. Moura et al. (2007), em gatos domiciliados, relataram $84,9 \%$ dos animais positivos. Estes autores observaram que a idade influencia fortemente a soroprevalência, com animais acima de doze meses apresentando sorologia positiva 12,3 vezes mais frequentemente que animais jovens. O mesmo também foi observado por Alvarado-Esquivel et al. (2007), no México, e por Rosa et al. (2010), em Lages, SC.

Não foi verificada correlação entre sorologia positiva para $T$. gondii e o sexo dos felinos (Tabela 1).

\section{CONCLUSÃO}

Os resultados do presente estudo permitem concluir que gatos apreendidos pelo Centro de Controle de Zoonoses de Lages, SC, apresentam elevada soropositividade para $T$. gondii e esta tem correlação com a idade dos animais, sendo mais comum nos animais com $\geq 13$ meses.

\section{NOTAS INFORMATIVAS}

Este projeto foi aprovado pelo Comitê de Ética em Experimentação Animal (CETEA) do CAV/UDESC sob número: 1.53.12.

\section{REFERÊNCIAS}

ALVARADO-ESQUIVEL, C.; LIESENFELD, O.; HERRERA-FLORES, R.G. et al. Seroprevalence of Toxoplasma gondii antibodies in cats from Durango City, Mexico. Journal of Parasitology, v.93, n. 5, p. 1214-1216, 2007.

BRAGA, M.S.C.O.; ANDRE, M.R.; JUSI, M.M.G. et al. Occurrence of anti-Toxoplasma gondii and anti-Neospora caninum antibodies in cats with outdoor access in Sao Luis, Maranhao, Brazil. Revista Brasileira de Parasitologia Veterinária, v. 21, n. 2, p. 107-111, 2012.

CAMARGO, M.E. Improvided technique of indirect immunofluorescence for serological diagnosis of toxoplasmosis. Revista do Instituto de Medicina Tropical, v. 6, n. 3, p.117-118, 1964.

CANTOS, G.A.; PRANDO, M.D.; SIQUEIRA, M.V. et al. Toxoplasmose: ocorrência de anticorpos anti-Toxoplasma gondii e diagnóstico. Revista Associação Médica Brasileira, v. 46, n. 4, p. 335-341, 2000.

CAVALCANTE, G.T.; AGUIAR, D.M.; CHIEBAO, D. et al. Seroprevalence of Toxoplasma gondii antibodies in cats and pigs from rural Western Amazon, Brazil. Journal of Parasitology, v. 92, n. 4, p. 863-864, 2006.

COELHO, W.M.D.; AMARANTE, A.F.T.; APOLINARIO, J.C. et al. Seroepidemiology of Toxoplasma gondii, Neospora caninum, and Leishmania spp. infections and risk factors for cats from Brazil. Parasitology Research, v. 109, n. 4, p. 1009-1013, 2011.

DABRITZ, H.A.; MILLER, M.A.; ATWILL, E.R. et al. Detection of Toxoplasma gondii-like oocysts 
in cat feces and estimates of the environmental oocyst burden. Journal of the American Veterinary Medical Association, v. 231, n. 11, p. 1676-1684, 2007a.

DABRITZ, H.A.; GARDNER, I.A.; MILLER, M.A. et al. Evaluation of two Toxoplasma gondii serologic tests used in a serosurvey of domestic cats in California. Journal of Parasitology, v. 93, n. 4, p. 806-816, 2007b.

DORNY, P.; SPEYBROECK, N.; VERSTRAETE, $\mathrm{S}$. et al. Serological survey of Toxoplasma gondii, feline immunodeficiency virus and feline leukaemia virus in urban stray cats in Belgium. Veterinary Record, v. 151, n. 21, p. 626-629, 2002.

DUBEY, J.P. Toxoplasma, Neospora, Sarcocystis and other tissue cyst-forming of human and animals. In: KREIER, J.P. Parasitic protozoa. 2 ed., San Diego: Academic Press, 1993. p. 1-157.

DUBEY, J.P.; NAVARRO, I.T.; SREEKUMAR, C. et al. Toxoplasma gondii infections in cats from Paraná, Brazil: seroprevalence, tissue distribution, and biologic and genetic characterization of isolates. Journal of Parasitology, v. 90, n. 4, p. 721-726, 2004.

DUBEY, J.P.; SU, C.; CORTES, J.A. et al. Prevalence of Toxoplasma gondii in cats from Colombia, South America and genetic characterization of $T$. gondii isolates. Veterinary Parasitology, v. 141, n. 1-2, p. 42-47, 2006.

GALVAN-RAMIREZ, M.L.; SANCHEZ-VARGAS, G.; VIELMA-SANDOVAL, M. et al. Presence of anti-Toxoplasma antibodies in humans and their cats in the urban zone of Guadalajara. Revista da Sociedade Brasileira de Medicina Tropical, v. 32, n. 5, p. 483-488, 1999.

GARCIA, J.L.; NAVARRO, T.I.; OGAWA, L. et al.. Soroprevalência do Toxoplasma gondii, em suínos, bovinos, ovinos e eqüinos e sua correlação com humanos, felinos e caninos, oriundos de propriedades rurais do norte do Paraná - Brasil. Ciência Rural, v. 29, n. 1, p. 9197, 1999.

LANGONI, H.; SILVA, A.V.; CABRAL, K.G. et al. Prevalência de toxoplasmose em gatos dos Estados de São Paulo e Paraná. Brazilian Journal of Veterinary Research Animal Science, v. 38, n. 5, p. 243-244, 2001.

MARTINS, C.S.; VIANA, J.A. Toxoplasmose - o que todo profissional de saúde deve saber. Clínica Veterinária, v.3, n. 15, p. 33-37, 1998.

MEERBURG, B.G.; VAN RIEL, J.W.; CORNELISSEN, J.B. et al. Cats and goat whey associated with Toxoplasma gondii infection in pigs. Vector Borne and Zoonotic Diseases, v. 6, n. 3, p. 266-274, 2006.

MEIRELES, L. R.; GALISTEO JUNIOR, A. J.; POMPEU, E. et al. Toxoplasma gondii spreading in an urban area evaluated by seroprevalence in free-living cats and dogs. Tropical Medicine and International Health, v. 9, n. 8, p. 876-881, 2004.

MIRO, G.; MONTOYA, A.; JIMENEZ, S. et al. Prevalence of antibodies to Toxoplasma gondii and intestinal parasites in stray, farm and household cats in Spain. Veterinary Parasitology, v. 126, n. 3, p. 249-255, 2004.

MOURA, L.; KELLY, P.; KRECEK, R.C. et al. Seroprevalence of Toxoplasma gondii in cats from St. Kitts, West Indies. Journal of Parasitology, v. 93, n. 4, p. 952-953, 2007.

NATALE, A.; FRANGIPANE DI REGALBONO, A.; ZANELLATO, G. et al. Parasitological survey on stray cat colonies from the Veneto Region. Veterinary Research Communications, v. 31, Suppl.1, p.241-244, 2007.

NAVARRO, I.T. Toxoplasmose. In: CONGRESSO BRASILEIRO DA ASSOCIAÇÃO DE VETERINÁRIOS ESPECIALISTAS EM SUÍNOS, 10, 2001, Porto Alegre. Anais... Disponível em <http://www.cnpsa.embrapa.br/abravessc/pdf/Palestras2001/Italmar_Navarro.pdf>. Acesso em: 03 de abril de 2011.

NETTO, E.G.; MUNHOZ, A.D.; ALBUQUERQUE, G.R. et al. Ocorrência de gatos soropositivos para Toxoplasma gondii Nicolle e Manceaux, 1909 (Apicomplexa: Toxoplasmatinae) na cidade de Niterói, Rio de Janeiro. Revista Brasileira Parasitologia Veterinária, v. 12, n. 4, p. 145-149, 2003.

ORTEGA-PACHECO, A.;ACOSTA-VIANA, K.Y.; GUZMAN-MARIN, E. et al. Infection dynamic of Toxoplasma gondii in two fattening pig farms exposed to high and low cat density in an endemic region. Veterinary Parasitology, v. 175, n. 3-4, p. 367-371, 2011.

PENA, H.F.J.; SOARES, R.M.; AMAKU, M. et al. Toxoplasma gondii infection in cats from Sao Paulo state, Brazil: seroprevalence, oocyst shedding, isolation in mice, and biologic and molecular characterization. Research in Veterinary Science, v. 81, n. 1, p. 58-67, 2006.

PFOHL, J.C.; DEWEY, C.W. Intracranial Toxoplasma gondii granuloma in a cat. Journal of Feline Medicine and Surgery, v. 7, n. 6, p. 369-374, 2005. 
ROSA, L.D.; MOURA, A.B.; TREVISANI, N. et al. Toxoplasma gondii antibodies on domiciled cats from Lages municipality, Santa Catarina State, Brazil. Revista Brasileira de Parasitologia Veterinária, v. 19, n. 4, p. 268-269, 2010.

SILVA, J.C.R.; GENNARI, S.M.; RAGOZO, A.M.A. et al. Prevalence of Toxoplasma gondii antibodies in sera of domestic cats from Guarulhos and São Paulo, Brazil. Journal of Parasitology; v. 88, n. 2, p. 419-420, 2002.

SVOBODOVÁ, V.; KNOTEK, Z.; SVOBODOVÁ, $\mathrm{M}$. Prevalence of $\lg G$ and $\operatorname{lgM}$ antibodies specific to Toxoplasma gondii in cats. Veterinary Parasitology, v. 80, p. 173-176, 1998.

WAAP, H.; CARDOSO, R.; LEITAO, A. et al. In vitro isolation and seroprevalence of Toxoplasma gondii in stray cats and pigeons in Lisbon, Portugal. Veterinary Parasitology, v. 187, n. 3-4, p. 542-547, 2012.

WANG, Q.; JIANG, W.; YONG-JUN, C. et al. Prevalence of Toxoplasma gondii antibodies, circulating antigens and DNA in stray cats in Shanghai, China. Parasites and Vectors, v. 5(190), 2012. doi:10.1186/1756-3305-5-190

WEIFENG, Q.; WANG, H.; SU, C. et al. Isolation and characterization of Toxoplasma gondii strains from stray cats revealed a single genotype in Beijing, China. Veterinary Parasitology, v. 187, n. 3-4, p.408-413, 2012. 